\title{
Assessment of the Physical-Chemical Properties of Stored Corn Submitted to a Treatment with Dusted Seeds of Moringa Oleifera Lam
}

\author{
C MN Oliveira ${ }^{1}$, S C De Paiva ${ }^{2}$, C AA Silva ${ }^{2}$ and AS Messias ${ }^{2 *}$ \\ ${ }^{1}$ Graduate student in the Master in Development of Environmental Processes, Catholic University of Pernambuco, Brazil \\ ${ }^{2}$ Teacher at Catholic University of Pernambuco, Brazil \\ *Corresponding author: A S Messias, Teacher at Catholic University of Pernambuco, Brazil
}

\begin{abstract}
ARTICLE INFO
Received: 嵫 January 24, 2020

Published: 蔧 February 04, 2020

Citation: C MN Oliveira, S C De Paiva, C AA Silva, AS Messias. Assessment of the Physical-Chemical Properties of Stored Corn Submitted to a Treatment with Dusted Seeds of Moringa Oleifera Lam. Biomed J Sci \& Tech Res 25(2)-2020. BJSTR. MS.ID.004180.
\end{abstract}

\begin{abstract}
The employment of phytosanitary agents applied trough seeds is common practice in corn crops. However, increasing concerns over the environment and living beings' safety bring to light a need for technologies, which aim at reducing the risks originated from manipulation of phyto protectors, which is one of Moringa oleifera Lam. main roles. It has been attempted to, therefore, evaluate the physiologic quality of corn seeds submitted to treatments with Moringa oleifera Lam. dusted seeds, with five repetitions, and doses equal to zero; 0,$5 ; 1.0 ; 2.0$ and 4.0 grams of moringa seed dust for each 10 grains of corn, with contact times of zero; 2; 4; 6 and 24 hours, 30 days (720 hours) and 6 months $(4,320$ hours). The measured parameters were germination test, humidity, volumetric weight, weight of 1,000 grains, ashes and acidity index. The results show that the physiologic quality of the corn seeds submitted to the application of Moringa oleifera Lam. suffered no impairment, turning its application technically viable for up to six months of storage.
\end{abstract}

Keywords: Grain Storage; Moringa; Physiologic Quality; Zea mays

\section{Introduction}

Brazil is a country, which presents a high potential for grain production that is yet to be fully explored. Corn is a widespread crop, for it adapts to the most different ecosystems. It covers, in the national territory, over 12 million hectares with an annual production of nearly 40 million tons of corn. Although it is a crop appropriate to the employment of high technology with the potential of producing over $16 \mathrm{t} /$ ha, low cost technologies prevail in the current scenario, which has kept the average national productivity around 2,5 t/ha [1]. Alongside the effort of increasing productivity, there necessarily must be an improvement in harvesting techniques and grain storage conditions. A positive trait of the grains is the possibility of being stored for a large amount of time with no significant losses in quality. However, prolonged storage is only feasible when proper measures of harvest, cleaning, drying, insect combat and fungi prevention are taken [2]. The preservation of seed quality during the storage period is one of the most important steps in the process of production and commercialization. The efforts under taken in production steps could turn ineffective should seed quality preservation fail, at least until a new sowing season starts [3]. [4] have concluded that the speed of deterioration of corn seeds during storage is mainly influenced by the starting physiologic quality of the seeds, as well as relative humidity and temperature of the environment.

The employment of phytosanitary products through seed application is common practice in corn crops, however, increasing concerns over environment and safety during the manipulation process led to a surge in demands for application technologies, which reduce risks without compromising seed quality $[5,6]$. Moringa oleifera Lam. is an unconventional tree greenery native to sub Himalayan regions in northwestern India, belonging to the Moringaceae family that is composed of a single genus (Moringa) with fourteen known species. It is a small shrub reaching a maximum of 12 meters high, with an open canopy with only a central trunk, possessing flowers that emerge in cream-colored 
panicles, known by several names according to their different uses; it is also known as "drumstick" for the form of its fruits which is a staple food in countries such as India and Africa $[7,8]$. The paste made of raw seeds is antibacterial; active substances are found in seed cotyledons, possessing three main components: "welloil", flocculator, both polypeptides (proteins), substances not yet clearly identified, and antimicrobial substance 4 - L - Rhamnosyl - oxybenzyl - isothio - cyanate (RI), according to $[9,10]$. The great concern with the environment has led numerous researchers to seek viable, effective and safe alternatives for the use of products applied during the corn grain storage process that allow commercialization, without quality. The purpose of the present study was to test the possibility of increasing corn grains storage times when treating them with dusted seeds of Moringa oleifera Lam. by preserving their physiologic quality.

\section{Materials and Methods}

The present study was conducted in the Laboratory of Analytic Chemistry of the Environmental Engineering department of the Catholic University of Pernambuco, Recife, Pernambuco, Brazil.

\section{Collection of Preparation of the Raw Materials}

Corn: The samples of corn BRS - Gorutuba employed in this study were provided by the Seed Laboratory (Seed Chamber) of the Agronomy Institute of Pernambuco - IPA, Recife/PE, Brazil, lot APRMG - 73/2014, 2014/2014 harvest, S-2 category, sent to storage and production in the year of 2014, corresponding to 25 tons, by the Center of Production and Commercialization - CPC of Petrolina, Recife/PE. After the homogenization of the collective sample, two final samples were withdrawn (of $2 \mathrm{~kg}$ each) to perform the laboratorial analysis. These samples were packaged individually in paper bags, wrapped in plastic bags, labeled and kept under refrigeration, at temperatures between 13 and $14{ }^{\circ} \mathrm{C}$ until used.

Moringa oleifera Lam: The moringa seeds were collected at the Center of Production and Commercialization - CPC of Petrolina, from the Agronomy Institute of Pernambuco - IPA, Recife/PE, Brazil, peeled and dried in an oven at $70^{\circ} \mathrm{C}$ for 30 minutes. After drying, the seeds were dusted and sieved at 14 mesh [7] and packaged in a sealed plastic recipient to prevent humidity exposure.

\section{Calculation of the Concentrations of Moringa Seed Dust and Contact Time with the Corn}

The treatments were performed with five repetitions, in doses of zero; $0.5 ; 1.0 ; 2.0$ and 4.0 grams of Moringa oleifera Lam. seed dust for each 10 grains of corn, with contact times of zero; $2 ; 4 ; 6$ and 24 hours, 30 days (720hours) and 6 months (4,320 hours). The relation between moringa dust $(\mathrm{mg} / \mathrm{g})$ and sedimentation time $(\mathrm{h})$ was adjusted according to a Composite Central Design (CCD) and their values combined in an experimental matrix.

\section{Performed Determinations}

Humidity: Water contained in the seeds is extracted in the form of vapor by the application of heat under controlled conditions. The recommended method was developed to reduce oxidation, decomposing or loss of other volatile substances while as high removal as possible of water. The determinations of humidity on the samples of corn and dusted moringa were performed before and after each treatment, which used a stove at $105^{\circ} \mathrm{C}$ for 24 hours [11]. The results were expressed in humidity percentage.

Germination Test: This test aims to determine de maximum potential of germination off a seed lot, which can be used to compare the quality of different lots and estimate the value required to sowing a field. In laboratory tests the percentage of seed germination corresponds to the proportion of seeds which have produced sprouts qualified as normal. The tests were performed according to the Rules of Seed Analysis - RAS [11], before and after each treatment, by sowing 10 corn seeds and germinating them wrapped between two or more paper towels germitest, humidified using deionized water, and left in the germinator (carefully washed with water and soap, then dried) in horizontal position (which represents the most recommended method for seeds of large crops, seeds of forage plants and vegetables of relatively large side which are not sensitive to light, known as RP), at a temperature of $25^{\circ} \mathrm{C}$, during five days when the assessment was performed. The results are expressed in percentage of normal sprouts.

Volumetric Weight: This parameter serves to establish the weight of a certain volume of seeds. Volumetric weight is a varietal trait, influenced by climate, soil, fertilization, cultivation system, occurrence of bugs and diseases, seed maturity, enhancing, the seed degree of humidity and chemical treatments. The volumetric weight was determined by weighting the grains in an electronic weight scale with a precision of $0.001 \mathrm{~g}$ from an amount fit in a $100.0 \mathrm{ml}$ beaker. The results of volumetric weight were expressed in $\mathrm{g} / \mathrm{ml}$.

Weight of 1,000 Grains: It has the objective of determining the weight of a thousand seeds from a sample. Such weight is employed in calculating the density of the sowing, the number of seeds per packaged and the weight of a sample to perform purity analysis when not specified by the Rules of Seed Analysis - RAS. It is an information which allows to roughly picture the side of the seeds, as well as their maturity and health status. The weight of 1,000 grains was determined through counting five repetitions of 100.0 grains of corn and weighting them in a precision scale. The results were multiplied by ten and expressed in grams.

Mineral Material or Ashes: The ashes content of a food is the name given to the inorganic remainder after burning the organic matter between $550-670^{\circ} \mathrm{C}$, which turns into $\mathrm{CO}_{2}, \mathrm{H}_{2} \mathrm{O}$ and $\mathrm{NO}_{2}$; being such, the ashes of a material are the starting point of an analysis of specific minerals. The beforementioned minerals are analyzed both with nutritional and safety intents. The content of ashes was determined using ceramic crucibles previously weighted at $600^{\circ} \mathrm{C}$, as describe by the Official Methods of Analysis [12], with previous incineration and calcination at $600^{\circ} \mathrm{C}$, in an mufla oven for 4 hours. Afterwards the sample was left to cool in a desiccator until it reached environmental temperature, when its weight was mea- 
sured. The results were obtained by the differences in the weights between the weight of the crucible and the weight of the crucible with the calcinated residue, considering the mass of the sample. Results expressed in percentages.

Acidity Index: The loss of quality of seeds and grains during storage is followed by a series of deteriorating modifications, even when it cannot be detected by any other means of viability loss, among which we remark the elevation of the free fatty acids. If the fatty acids - FA are the components of oils and fats, in mono, di and triglycerides then a large amount of free FA points that the product is in fast process of deterioration. The main consequence of that is turning the acidification of the material. An elevated level of acidity indicates, therefore, that the oil or fat is suffering disruptions in is chain, releasing its main components, the FA, and for that reason the measurement of such index is of paramount importance in assessing the state of deterioration (hydrolytic rancidity) of the oil or fat that is consumed.

According to the methodology described by the AOAC [12], the acidity index is determined by adding $150.0 \mathrm{ml}$ of ethylic alcohol (ethanol) in the treatments and in a blank sample, leaving it to rest for 30 minutes, performing agitations each five minutes. The following step is to filter the supernatant in a paper filter of $0.5 \mathrm{~mm}$; moving it to an erlenmeyer of $250.0 \mathrm{ml}$. The titration with a standard solution of $\mathrm{NaOH} 0.02 \mathrm{M} \mathrm{f}=0.9998$ was performed until a pink color appeared while using a phenolphthalein solution at $1 \%$ as indicator. The acidity index was expressed in percentages.

\section{Results and Discussion}

\section{Humidity}

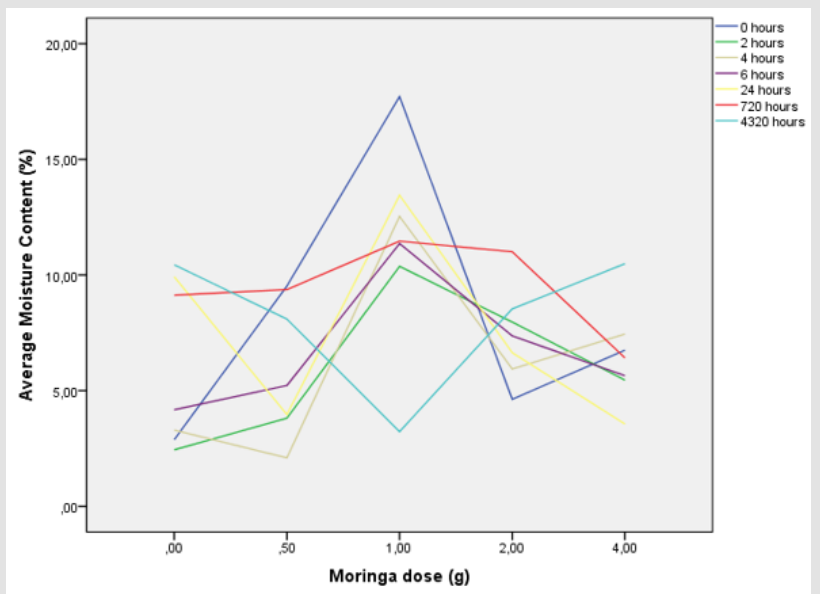

Figure 1: Humidity content of the corn grains in the different treatments.

The results shown in Figure 1 indicate that the humidity content of the samples analyzed in this study has ranged from 2.09 (0.5g Moringa/4h Contact) to $13.45 \%$ (1.0g Moringa/24h Contact), which are all below the maximum value allowed by the Ministry of Agriculture (14.5\%) according to the regulation n. 845 from 1976
[13]. Only the treatment of $1.0 \mathrm{~g}$ Moringa/0h Contact presented a value above the permitted (17.71\%). Such contents of humidity, found in the corn samples studied, could have contributed to their level and frequency of contamination (data not presented). In samples of stored corn, the absence of contamination has been attributed to humidity levels between 13 and 13.5\% [14]. The development of fungi in corn with humidity content of $14 \%$ after storage periods of up to 62 days [15]. In this study, the longest period of storage was 6 months $(4,320$ hours $)$ in the treatment of 4.0g Moringa/6 months Contact.

\section{Germination Test}

The percentage results of the germination of seeds from the hybrid BRS - Gorutuba, both treated and untreated with moringa, it could be verified that seeds subject to phytosanitary treatment generated normal sprouts, which indicates a non-phytotoxic effect of the products over the seeds. It must be highlighted that the seeds presented a good initial quality and the reduction of germination on the treated seeds was only $1 \%$, which validates the possibility of employing moringa to protect the seeds. As stated by [16], the storage potential of seeds is directly related to their initial quality, because a lot of high quality could be stored for longer periods of time, in uncontrolled conditions than one which its initial quality is compromised. Hence the positive results presented with the moringa treatments. It has also been verified that, even with six months of storage, the seeds still kept a percentage of germination above the established minimum for commercialization, which is $85 \%$ [17].

\section{Volumetric Weight/ Weight of 1,000 grains}

Regarding the volumetric weight of the corn seeds, it was found, on average, a value of $78.95 \mathrm{~g} / \mathrm{ml}$ and an average weight of a thousand grains of $355.39 \mathrm{~g}$. Such data corroborate the ones found in germination and humidity, since it could be related to a greater robustness of the seeds employed in the experiment, which is in accordance to what was observed by [18-20]. The results show, not only in volumetric weight but also in the weight of a thousand seeds, that the seeds presented satisfactory criteria in terms of quality, which, in a way, agrees with [18]. Such verification was key, bearing in mind the goal of the study. It must be stressed out, however, due to the novel aspect of the research, further studies on the subject are needed.

\section{Mineral Material or Ashes}

The corn seeds presented, in the verification of ash content (Figure 2), a percentage ranging from 3.42 to $20.17 \%$, represented by the treatments of $1.0 \mathrm{~g} \mathrm{M} / 30$ days Contact and $2.0 \mathrm{~g} \mathrm{M} / 6 \mathrm{~h}$ Contact, respectively. The mineral content found was considered high, since the maximum value established by the current legislation is $1.4 \%$. Therefore, the ash content found in all treatments was above permitted. Even though it was not affected by the presence of the moringa, ash content increased in function of increasing levels 
of moringa/contact, because, as stated by [21], the availability of minerals influences the mineral composition of the corn grains.

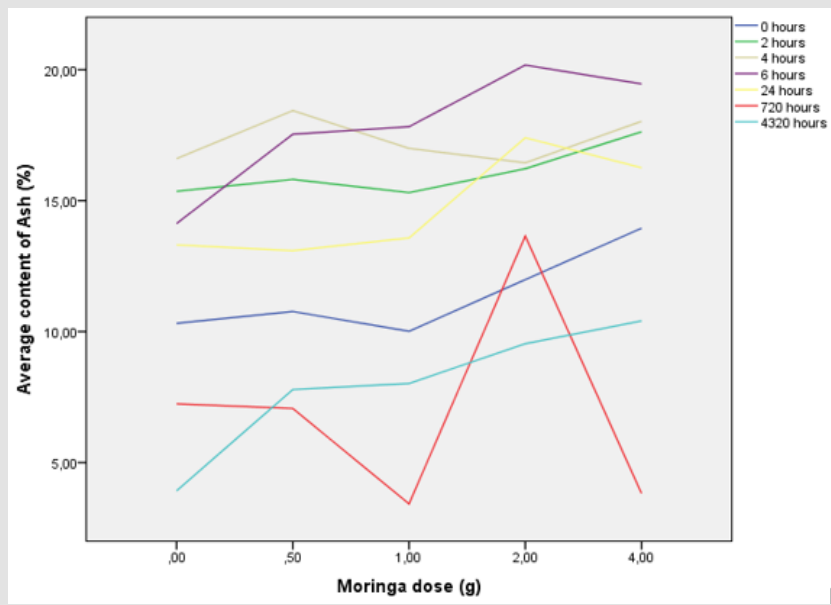

Figure 2: Percentage of ashes in corn grains in the different treatments applied.

\section{Acidity Index}

In Figure 3 are presented the acidity index values of corn after the different treatments employed. There have been found, on average, values of $0.35 \%(0 \mathrm{~g} \mathrm{M} / 6$ monthsContact) up to $5.83 \%$ (4.0gM/6monthsContact), which point to the fact that the results could be directly related to the presence of insects and fungi amid the grains. An elevated acidity index (above 5\%) indicates, therefore, that oil or fat are suffering disruptions in their chains, releasing their main components, fatty acids. That is why measuring this index is of extreme importance in assessing the hydrolytic rancidity of the oil or fat that is being consumed. As stated by [22], insects are the major cause of deterioration and losses during storage. They damage the grains, exposing their inner parts, which facilitates the development of fungi. Their infestation damages the vegetal tissue of this grain, producing carbonic gas $\left(\mathrm{CO}_{2}\right)$ and water $\left(\mathrm{H}_{2} \mathrm{O}\right)$, from grain respiration, which contribute to increasing humidity and, consequentially temperature, which in turn makes fungi multiplication easier (non-presented data).

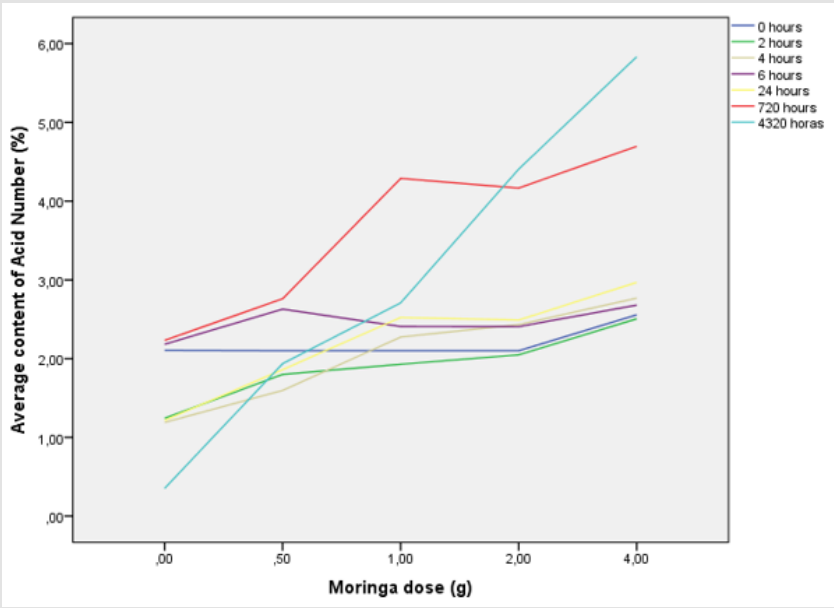

Figure 3: Percentage of acidity index of corn grains in the different employed treatments.

\section{Conclusion}

In the conditions in which this study was performed, it can be concluded that: The content of humidity in all corn treatments was lower than the maximum value permitted by the Ministry of Agriculture $(14.5 \%)$. The hybrid BRS - Gorutuba corn seeds subjected to the phytosanitary treatment with moringa presented normal sprouts, which indicates a non-phytotoxic effect of the product over the seeds. Film coating did not affect the physiologic quality of corn seeds and did not interfere in the treatments in the seeds with starting high quality. Volumetric weight can be employed as a satisfactory indicator to assess corn seed quality. The weight of a thousand seeds can be employed as an auxiliary indicator of volumetric weigh in assessing the quality of the stored corn seeds. The application of Moringa oleifera Lam. on corn seeds is technically viable. From what has been observed, further research over the subject is needed, including a possible relationship between volumetric weight and the traits that mark seed robustness.

\section{Acknowledgements}

The authors are grateful to the Coordination of Improvement of Higher Education Personnel (CAPES) for the master's scholarship, to the Foundation for the Support of Science and Technology of the State of Pernambuco (FACEPE) for the research aid, to Agronomic Institute of Pernambuco (IPA) for the physical space, to the Consortium Universities for the research aid and to the Analytical Chemistry Laboratory of Catholic University of Pernambuco for the support in the experiments.

\section{Competing Interests}

Authors have declared that no competing interests exist.

\section{References}

1. (2014) Projections of Agribusiness Brazil - 2014-2015 to 2024-2025. Agriculture Livestock and Supply.

2. Souza OW, Silagem de milho úmido, Lorini I, Miike LHE, Scussel VM (2002) Grain storage. Campinas: IBG 859-885.

3. Carvalho MLM (1992) Refrigeration and quality of corn seeds stored in piles with different packages. ESALQ: Piracicaba pp. 986.

4. Bewley JD, Black M (1994) Seeds: physiology of development and germination. (2 edn.).

5. Ndabigengesere A, Narasiah SK (1996) Influence of operating parameters on turbidity removal by coagulation with Moringa oleifera seeds. Environmental Technology 17(10): 1103 - 1112.

6. Muyibi SA, Evision LM (1995) Moringa oleifera seeds for softening hard water. Water Research 29(4): 1099-1104.

7. Gomes Filho AJ, Paiva SC, Takaki GMC, Messias AS (2019) Application of Moringa in the removal of salts from the desalinator reject. Current Journal of Applied Science and Technology 36(1): 1-13.

8. Alves, MM (2015) Use of Moringa oleifera seed in the physical chemical treatment of fish farm wastewater. ROCA.

9. Santana PMA, Messias AS (2019) Cadmium sorption by Moringa oleifera Lam. Asian Journal of Environmental and Ecology 11(2):1-7.

10. Francisco, Adriana Ribeiro (2012) Coagulation with Moringa oleifera followed by slow filtration in the reduction of Cryptosporidium spp. by simulation with polystyrene microspheres. BDTD. 
11. (2009) Rules for Seed Analysis. Ministry of Agriculture, Livestock and Supply Agricultural Defense Secretariat pp. 1-395.

12. (2016) Official Methods of Analysis Chemical of AOAC International. $\left(20^{\text {th }}\right.$ edn.). EBC.

13. (1976) Approve the Specifications for the Standardization, Classification and Internal Marketing of Corn. Ministry of Agriculture.

14. Prado G, Vieira MBCM, Santos JP, Oliveira MSD (1995) Ocorrência de micotoxinas em milho pós-colheita e armazenado do Estado de Minas Gerais, safra 1991. Higiene Alimentar 9 (35): 24-27.

15. Sérgio de Oliveira Juchem, Everton Luis Krabbe, Antônio Mário Penz Junior, Marcus Fernando Reginatto (1994) Effect of moisture and propionic acid on the bromatological and microbiological characteristics of corn grains. 27-28.

16. Fratin, P (1992) Comparação entre métodos para a avaliação da qualidade fisiológica de sementes de milho (Zea mays L.). 67.

ISSN: 2574-1241

DOI: $10.26717 /$ BJSTR.2020.25.004180

A S Messias. Biomed J Sci \& Tech Res

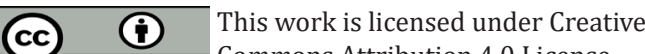

Submission Link: https://biomedres.us/submit-manuscript.php
17. Brasil. Ministério da Agricultura. Normas, padrões e procedimentos para a produção de sementes básicas, certificadas e fiscalizadas. $\left(2^{\text {nd }}\right.$ edn.). Belo Horizonte, 1985: 110.

18. Okada T (1978) Studies on Green panic seed. The use of seed volume weigt in estimating of Green panic seed. Journal Japanese Society of Grassland Science 24(2):133-136.

19. Toledo FF, Marcos Filho J (1977) Seed manual: production technology. Sao Paulo Agronomica Ceres.

20. Silvio Moure Cicero, Eujanir W de Lima Orsi (1977) Influence of rice seed weight (Oryza sativa L.) on germination. Scielo.

21. Ferreira ACB, Araújo GAA, Pereira PRG, Cardoso AA (2001) Agronomic and Nutritional Characteristics of Corn Fertilized with Nitrogen, Molybdenum and Zinc 58: 131-138.

22. Faroni LRD, Barbosa GNO, Sartori MA, Cardoso FS, Alencar ER (2005) Qualitative and Quantitative Evaluation of Maize in Different Storage Conditions 13(3):193-201.

$\begin{array}{ll}\text { BIOMEDICAL } & \text { Assets of Publishing with us } \\ \text { RESEARCHES } & \text { - Global archiving of articles } \\ & \text { - Immediate, unrestricted online access } \\ & \text { - Rigorous Peer Review Process } \\ & \text { - Anttps://biomedres.us/ }\end{array}$

